\title{
Comunicación bidireccional entre el sistema inmune y neuroendocrino a través de la hormona de crecimiento, prolactina y hepcidina
}

\section{Bidirectional communication between neuroendocrine and immune systems through growth hormone, prolactin and hepcidin}

\author{
Cruz Enríquez V,* M.Sc, Paola Paez R, M.Sc, Rómulo Campos G, Ph.D.
}

Universidad Nacional de Colombia Sede Palmira. Facultad de Ciencias Agropecuarias, Departamento de Ciencia Animal. Palmira, Colombia.*Correspondencia: ceenriquezv@unal.edu.co.

Recibido: Marzo de 2011; Aceptado: Septiembre de 2012.

\section{RESUMEN}

Se ha planteado que la hormona de crecimiento $(\mathrm{GH})$ y la Prolactina (PRL) pueden intervenir en procesos infecciosos como inmunomoduladores vía receptores específicos; revelando una conexión entre el sistema inmune y el sistema endocrino en los tejidos, donde actúan como citoquinas a través de diferentes rutas de señalización. Igualmente, la hepcidina (HAMP), hormona producida en los hepatocitos como respuesta al exceso de hierro y a estímulos inflamatorios, es considerada un enlace entre el metabolismo del mineral, la defensa del hospedero y los procesos inflamatorios, debido a su capacidad de privar del hierro a los microorganismos. Se sugiere que en un proceso infeccioso, la síntesis, secreción y regulación de GH ocurre a través de la producción de citoquinas como factor de necrosis tumoral alfa (TNF- $\alpha$ ) e interleuquina- 1 beta (IL-1 $\beta$ ), las cuales actúan en el hipotálamo, estimulando la liberación ya sea de la hormona liberadora de somatotropina o de somatostatina; por otro lado, se ha reportado que células linfoides, incluyendo linfocitos T y B y células dendríticas, producen $\mathrm{GH}$, PRL biológicamente activa con propiedades inmunoreguladoras.

Palabras clave: Hormona de crecimiento animal, prolactina, sistema inmune (Fuente:CAB).

\begin{abstract}
It has been proposed that growth hormone $(\mathrm{GH})$ and prolactin (PRL) may act as immunomodulators in infectious processes via specific receptors, revealing a connection between the immune and endocrine systems in the tissues where they act as cytokines through different signaling pathways. Similarly, hepcidin (HAMP), a hormone produced in hepatocytes in response to excess iron and inflammatory stimuli, is considered a link between mineral metabolism, host defense and inflammatory processes because of its ability to deprive microorganisms of iron. It is suggested that in an infectious process, synthesis, and regulation of $\mathrm{GH}$ secretion occurs through the production of cytokines such as necrosis factor-alpha (TNF-a) and interleukin-1 beta (IL-1 $\beta$ ), which act in the hypothalamus by stimulating the release of either somatostatin or somatotropin hormones; on the other hand, it has been reported that lymphoid cells including $\mathrm{T}$ and $\mathrm{B}$ lymphocytes and dendritic cells produce $\mathrm{GH}$, and biologically active PRL with immunoregulatory properties.
\end{abstract}

Key words: Growth hormone, immune system, prolactin (Source:CAB). 


\section{INTRODUCCIÓN}

Por más de cuatro décadas, se ha documentado que entre el sistema nervioso central (SNC) y el sistema inmune (SI) ocurren interacciones por medio de rutas bidireccionales, las cuales se basan en la secreción de citoquinas, hormonas, neurotransmisores y neuropéptidos $(1,2)$.

Evidencias soportan la existencia de comunicación bidireccional entre el SI y el eje somatotrófico en varias especies, asimismo, se ha reportado que tanto la hormona de crecimiento $(\mathrm{GH})$ como prolactina ( $P R L)$ ejercen efectos benéficos sobre el SI actuando como inmunomoduladores, ya que mejoran la proliferación de linfocitos T (3) y estimulan la liberación de citoquinas y de óxido nítrico por parte de los macrófagos (4). Por otro lado, hepcidina (HAMP), una hormona peptídica producida en el hígado en respuesta a estímulos inflamatorios y exceso de hierro, además de controlar negativamente la absorción de este mineral y la liberación de hierro de los macrófagos, se ha descrito que actúa como péptido antimicrobial (5), por lo que, se considera ser un puente de conexión fundamental entre la inmunidad innata y el metabolismo del hierro (6).

El conocimiento de las rutas de comunicación, así como de los mecanismos, acción biológica y efectos que ejerce el sistema neuroendocrino a través de la GH, PRL y HAMP, puede ser de gran interés, dado que a partir de estos, se podrían formular estrategias que permitan prevenir pérdidas económicas asociadas a enfermedades en animales de interés zootécnico. El objetivo de la presente revisión fue presentar una sinopsis de un tipo de comunicación entre el sistema endocrino y el SI, conocer los efectos biológicos y los mecanismos de acción que ejercen GH, PRL y la HAMP entre sí, y el papel de su interacción en la respuesta inmune.

\section{Comunicación entre los sistemas inmune y neuroendocrino a través de hormonas, neurotransmisores y citoquinas. La existencia de una ruta de comunicación entre varios productos hormonales del sistema endocrino y el SI ha sido documentada en una variedad de especies por más de cuatro décadas.}

Desde 1965, investigadores revelaron una conexión entre el SI y el sistema neuroendocrino, por medio de comunicaciones bidireccionales (7). Esta comunicación utiliza un lenguaje bioquímico mediante hormonas, neurotransmisores y citoquinas producidas por los propios sistemas y que pueden actuar como inmunomoduladores y reguladores metabólicos, por una vía común de receptores en ambos sistemas (8).
El sistema nervioso puede afectar al SI a través de dos rutas: el eje neuroendocrino y el sistema nervioso autónomo.

La ruta neural simpática y parasimpática regula la respuesta inmune innata a nivel regional, local y sistémico, a través de mediadores, péptidos neurotransmisores relacionados con el gen de la calcitonina, la somatostatina, la sustancia P y el neuropéptido Y (NPY) (9), los cuales, actúan directamente sobre los receptores ubicados en la membrana de otras neuronas o sobre diversos tipos de células blanco, estimulando la secreción de citoquinas y neuropéptidos; por ejemplo, estimulan la secreción de citoquinas de las diferentes poblaciones de células $T$ ayudadoras (Th), específicamente Th1 y Th2 (10).

De igual forma, varias hormonas y sus receptores han sido identificados en tejidos y células asociados al sistema inmunológico, y se ha demostrado que participan en el desarrollo, diferenciación y regulación de la respuesta inmune durante la activación de linfocitos mediada por la presencia de antígenos, probablemente actuando en forma autocrina/paracrina (8).

Por otro lado, se ha comprobado que los linfocitos son capaces de producir hormonas como GH, PRL, hormona adrenocorticotropa (o corticotropina) (ACTH), hormona estimulante de la tiroides (TSH), factor de crecimiento insulínico (IGF-1), leptina y gonadotropinas (11) e, igualmente, tanto en estudios in vivo como in vitro, se ha reportado la expresión de HAMP en neutrófilos y macrófagos (12), así como en linfocitos de peces y humanos (13).

Además, diversas citoquinas también pueden ser secretadas por células del SNC en varios sitios del cerebro: interferón alfa (IFN-a) e interferón gama (IFN- $\gamma$ ), interleuquina-1 (IL-1), interleuquina-2 (IL-2) e interleuquina-6 (IL-6), las cuales se ha demostrado que son producidas principalmente por astrocitos y microglia (14).

Dentro de las principales citoquinas involucradas en la comunicación sistema inmune- sistema nervioso (SI-SN) están: IL-1, TNF-a, IL-2, IL-6, IFN- $\gamma$, interleuquina-12 (IL-12) e interleuquina-10 (IL-10)(15). La IL-2, una citoquina producida por las células Th, parece ejercer efectos sobre las células neuroendocrinas y las neuronas, estimulando la producción de ACTH por parte de las células de la adenohipófisis. Igualmente, en ratas IL-1 incrementa las concentraciones plasmáticas de ACTH y estimula la liberación de GH, hormona luteinizante (LH) y hormona folículo estimulante (FSH) en las células adenohipofisarias (11) e IL-6, citoquina producida por los macrófagos, induce la 
síntesis de HAMP durante la inflamación a través de la activación de la cascada de transductores de señales y activadores de proteínas de transducción 3 (STAT3)(6).

Así, estos neurotransmisores, neuropéptidos, interleuquinas, quimoquinas, interferones y hormonas interactúan con receptores ubicados en las células de ambos sistemas SNC y SI, permitiendo al SNC detectar alteraciones en la actividad inmune mediante un sistema sensorial molecular; después de la detección, se inicia un cambio en la respuesta inmune en presencia de los estímulos condicionados (10).

\section{Acciones biológicas de la (GH) sobre el sistema inmune. La GH es una hormona proteica que contiene 191 aminoácidos, sintetizada y secretada en la hipófisis anterior, controlada por dos hormonas de acciones antagónicas secretadas por las células neurosecretoras del hipotálamo: la hormona liberadora de la somatotropina, un péptido sintetizado en el núcleo arcuato, el cual estimula la secreción de $\mathrm{GH}$ y la somatostatina, producida en el núcleo paraventricular, que se encarga de inhibir la liberación de GH (16).}

Otro péptido de importancia en el control de GH es la Ghrelina; péptido de 28 aminoácidos originalmente aislado de estómago de ratas como un ligando endógeno del receptor de secretagogos de la hormona de crecimiento (GHS-R) (17). En ganado, recientemente investigadores han demostrado en experimentaciones in vivo que ghrelina estimula la secreción de GH (18).

La GH está involucrada principalmente en el crecimiento y en el metabolismo. Sin embargo, en mamíferos se ha demostrado que la GH también funciona como un modulador importante del SI. Así por ejemplo, Redelman et al (3), reportan que GH y PRL incrementan el número de timocitos. Sodhi y Tripathi (19), en estudios in vitro donde investigaron el perfil de citoquinas secretadas por macrófagos cuando eran tratados con $\mathrm{GH}$ y $\mathrm{PRL}$, reportan que ambas hormonas mejoraron significativamente la producción de

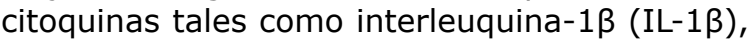
interleuquina-12p40 (IL-12p40) e IFN- ${ }^{-}$, además, indujeron la producción de quimoquinas como proteína inflamatoria de macrófagos- 1 beta (MIP-1 $\beta$ por sus siglas en inglés macrophage inflammatory protein). Baeza et al (20), en sus estudios en ratas macho encontraron que la terapia con GH mejora las funciones del SI, en otro estudio, Baeza et al (21), utilizando ratas ovariectomizadas y enteras demostraron que la administración de $\mathrm{GH}$, melatonina y estrógenos, estimulan la linfoproliferación en ambos grupos, además de ser efectivos para estimular los niveles de IL-2 y la actividad de las células asesinas (Naturall Killer NK), Asimismo, recientemente Frare et al (22), en un estudio in vivo utilizando ratas macho infectados con Trypanosoma cruzi, reportaron que animales tratados con $\mathrm{GH}$ muestran menor cantidad de tripomastigotes en sangre que ratas no tratadas y que las tratadas con GH tienden a producir altas concentraciones de factor de necrosis tumoral alfa (TNF-a), IFN- $\gamma$ y óxido nítrico comparado con las ratas no tratadas, sugiriendo que $\mathrm{GH}$ puede ser considerada como una sustancia inmunomoduladora para controlar la replicación de parásitos.

En un proceso infeccioso, la producción y regulación de citoquinas proinflamatorias (principalmente IL- $1 \beta$, IL-6, IL-12 TNF-a, IFN- $\gamma$ ) por las células del sistema inmune innato (macrófagos y monocitos) al sitio de inflamación e infección, induce una reacción de fase aguda caracterizada por fiebre, anorexia, modificaciones metabólicas tales como catabolismo de proteínas, lipólisis y gluconeogénesis, incremento de síntesis de proteínas de fase aguda en el hígado, además de cambios hormonales en los cuales se involucra el eje somatotrófico GH/IGF-1 (13).

El proceso inicia con una serie de reacciones en las cuales el SI trabaja continuamente para inhibir la invasión de los microorganismos y evitar daños en el tejido afectado; por ejemplo, durante una infección por bacterias Gram-negativas, la primera línea de defensa es la respuesta innata, la cual es activada inmediatamente después del contacto. Las células inmunes innatas reconocen a la bacteria por medio de receptores que funcionan como "señalizadores de peligro" como son los receptores Toll (TLRs), que son una familia de receptores que reconocen una diversidad de patrones moleculares asociados a patógenos PAMPS (por sus siglas en inglés Pathogen Associated Molecular Pattern) y son expresados en diferentes tipos de células, incluyendo monocitos, células dendríticas y células NK. Estos TLRs reconocen los lipopolisacáridos de la membrana celular bacterial (LPS) e inician la respuesta inflamatoria con la subsecuente producción de citoquinas proinflamatorias (principalmente, IL-1, TNF-a, IL-6). Este proceso se inicia mediante la unión TLRs-PAMPS, activando la cascada de señalización receptor-Toll/IL-1 (TIR) y secuencialmente la transducción de señales y la traslocación del factor nuclear NF-kB, encargado de la transcripción de genes de citoquinas, quimoquinas, proteínas del complemento y moléculas de adhesión que, participan en la respuesta innata a través del reclutamiento y la activación de células inflamatorias. 
Además, del flujo de citoquinas, quimoquinas, proteínas del complemento y moléculas de adhesión, estudios in vivo e in vitro reportan que en una respuesta inmune, los LPS inducen cambios de GH e IGF-1 en animales domésticos. Briard et al $(23,24)$, afirmaron que, en ovejas, la administración de endotoxinas de Escherichia coli estimula los niveles plasmáticos de $\mathrm{GH}$; $\sin$ embargo, con algunas contradicciones entre autores, se ha reportado que los cambios en las concentraciones de $\mathrm{GH}$ frente a una respuesta inmune es específica entre especies. Por ejemplo, en humanos, ovejas y cerdos se incrementan las concentraciones de GH con la activación del SI, mientras que en ratas y pájaros se ha reportado su disminución (7). No obstante, Priego et al (25), reportaron que cuando se administran dosis bajas de LPS $(10 \mu \mathrm{g} / \mathrm{kg})$ en ratas, se incrementan las concentraciones de $\mathrm{GH}$ plasmáticas, mientras que cuando se aplican dosis altas de LPS (100 $\mu \mathrm{g} / \mathrm{kg}$ ) las concentraciones plasmáticas de $\mathrm{GH}$ disminuyen, indicando que las diferencias observadas fueron debido a la dosis de LPS y no a diferencias entre especies.

A pesar de que estos resultados demostraron que en una respuesta inmune los LPS inducen cambios en el eje somatotrófico (GH/IGF-1), la ruta de comunicación que estimula este efecto era desconocido. Para averiguar esto, Daniel et al. (26), desarrollaron una serie de experimentos para determinar si el desafío intravenoso de TNF-a e IL- $1 \beta$ podría incrementar la GH en ovejas. En sus resultados demostraron que, la aplicación intravenosa de TNF-a e IL-1 $\beta$ induce un rápido incremento en las concentraciones circulantes de $\mathrm{GH}$, el cual ocurre de una forma bifásica por más de 2 horas, sugiriendo que los LPS podrían liberar o aumentar las concentraciones de $\mathrm{GH}$ por una acción directa sobre el hipotálamo, posiblemente a través de la regulación de somatostatina o de la hormona liberadora de somatotropina o de ambas. Igualmente, en el mismo año Priego et al (27), reportan que la administración de $100 \mu \mathrm{g} /$ $\mathrm{kg}$ de LPS en ratas incrementan los contenidos de RNAm de somatostatina hipotalámica, respaldando la idea que posiblemente los LPS modifican las concentraciones de GH por medio de la regulación de somatostatina.

Teniendo en cuenta los resultados de Priego et al $(25,27)$, y de Daniel et al $(26)$, se sugiere que el reconocimiento de LPS por parte de receptores del SI posiblemente activa a las células (macrófagos y monocitos) e induce la producción de citoquinas TNF-a e IL-1 $\beta$, las cuales actúan a nivel de hipotálamo estimulando la síntesis y secreción de $\mathrm{GH}$; pero altas dosis de LPS puede inducir un incremento en la liberación de somatostatina, con la subsecuente inhibición en la liberación de
$\mathrm{GH}$. Sin embargo, a pesar de estos resultados, es posible que otros mecanismos sean los responsables de los cambios de $\mathrm{GH}$ inducido por LPS. Wang et al (28), en una investigación in vivo en ratones, reportaron que LPS inducen insensibilización de $\mathrm{GH}$ a través de la proteólisis de su receptor (GHR).

Mecanismos de acción de GH. Se ha planteado que $\mathrm{GH}$ puede actuar en los tejidos linfoides como una citoquina, ya que comparte mecanismos con una gran familia de citoquinas y quimoquinas, sugiriendo que, aquellas moléculas poseen mecanismos regulatorios en común. Esta posibilidad de comunicación cruzada entre GH y algunas citoquinas está parcialmente basada en el hecho de que la ruta de señalización JAKSTAT (Janus Kinasa-transductor de señales y activador de factores de transcripción) que se activa por la unión de GH a su receptor GH-GHR, está involucrada en numerosos procesos de señalización utilizado por citoquinas del SI, en los que se incluye IFN-r, interleuquina 13 (IL-13), interleuquina 3 (IL-3), interleuquina 5 (IL-5), IL-6 y IL-12, entre otros (3).

El IFN-r utiliza Janus kinase-1 (JAK-1), Janus Kinase-2 (JAK-2) y activa principalmente la proteína de transducción 1 (STAT-1), quien efectúa la transcripción de múltiples efectores inmunes, genes de proteínas y complejos inflamatorios tales como Complejo principal de Histocompatibilidad (MHC), moléculas proinflamatorias, proteínas del complemento y enzima óxido nítrico sintetasa (29). IL-12 e interleuquina-4 (IL-4) activan las proteínas de transducción 4 y 6 (STAT4 y STAT6), los cuales son esenciales para el desarrollo de poblaciones de linfocitos Th1 y Th2. Los interferones (IFNs) también activan las proteínas de transducción 2 (STAT2), el cual media la respuesta antiviral e IL-2, IL-4 e interleuquina 15 (IL-15) activan las proteínas de transducción 5 (Stat5a y Stat5b) quienes participan en la proliferación de linfocitos.

Al respecto, Tripathi y Sodhi (30) reportaron que la respuesta proinflamatoria de macrófagos inducida por GH está mediada por las rutas de señalización JAK2/PI3K/PKC (Janus quinasa 2/ fosfatidilinositol 3 Cinasa/ Proteína quinasa C), JAK2/JNK (Janus quinasa 2/ C-jun amino terminal quinasa) y JAK/STAT. Además, GH induce y mejora la expresión y fosforilación de factores de transcripción C-Phos, C-Jun, Elk-1 y STAT1, los cuales regulan la expresión génica de citoquinas proinflamatorias.

Acciones biológicas de la PRL sobre el sistema inmune. La PRL es una hormona polipeptídica de una sola cadena, la cual consta 
de 198 aminoácidos con un peso molecular de $23.5 \mathrm{kDa}$ (31). La PRL ejerce efectos sobre la reproducción y la lactancia, pero desde 1930 se ha documentado el papel de esta hormona en la modulación del SI (32).

Se ha reportado que, células linfoideas, incluyendo linfocitos T y B y células dendríticas, producen PRL biológicamente activa. Asimismo, una gran cantidad de literatura de estudios in vivo, in vitro y estudios clínicos indican que la PRL ejerce propiedades inmunoreguladoras a través de su receptor (PRLR). Al igual que $\mathrm{GH}$, la unión de la PRL a su receptor activa la ruta de señalización JAK/STAT, la cual es compartida con otras hormonas neuroendocrinas y citoquinas que hacen parte de la respuesta inmune, sugiriendo la posibilidad de comunicación cruzada entre ellos (33).

La PRL también puede actuar en la proliferación de timocitos, sin embargo, sus mecanismos de acción no han sido completamente dilucidados. Recientemente, Xu et al (33), reportaron que, la PRL secretada por los linfocitos $T$ es un importante inmunoregulador local porque actúa como un factor de crecimiento en la regulación de la proliferación de linfocitos durante la respuesta inmune, ya que mejora la producción de moléculas coestimuladoras (moléculas como CD40, CD28, CD152) y citoquinas, que son esenciales para la activación de linfocitos $T$, pues en ausencia de PRL y de su receptor, la expresión de moléculas coestimuladoras como CD137, CD154 y citoquinas como IL-2 e IL-4 se redujo.
En la activación de las células $T$, además del receptor de antígeno de linfocitos T (TCR) y el antígeno, para que la activación y reacción de los linfocitos T (LT) sea óptima, se requiere que LT y la célula presentadora de antígeno (CPA) se unan y se comuniquen entre sí (Figura 1) (34); esta comunicación se hace por medio de moléculas coestimuladoras como CD40 (CD40L o CD154), las cuales son expresadas en los linfocitos $T$ de ayuda entre 4 y 24 horas después de que su TCR ha sido activado por antígeno. Una vez expresado CD154, se une a su contra receptor CD40 que se expresa en CPA y esta unión genera emisión de señales en ambos sentidos, es decir, desde LT hacia CPA y desde CPA hacia LT. La señal que llega a LT lo estimula a expresar CD28 y la que llega a CPA la estimula a expresar CD80, CD86 o ambas; tanto CD28 como CD80 o CD86 se unen para completar la activación del LT. Esta unión estimula al LT a expresar la molécula coestimuladora CD152, también conocida como CTLA-4, y de esta forma, permanecer activados para la óptima producción y proliferación de citoquinas. Asimismo, la unión de CD40 y CD154 también estimula a CPA a producir citoquinas como IL-1, IL-6, IL-8, IL-12 y TNF-a. En ausencia de CD28, los LT no se activan y en ausencia de CD152, los LT sufren activación descontrolada (34); por lo tanto, es evidente que dichas moléculas coestimuladoras son esenciales para la activación correcta de los linfocitos $\mathrm{T}$ y la subsecuente reacción inmunológica.

Igualmente, se ha reportado que, la PRL puede apoyar indirectamente la proliferación de timocitos estimulando la síntesis de IL-2 (2)

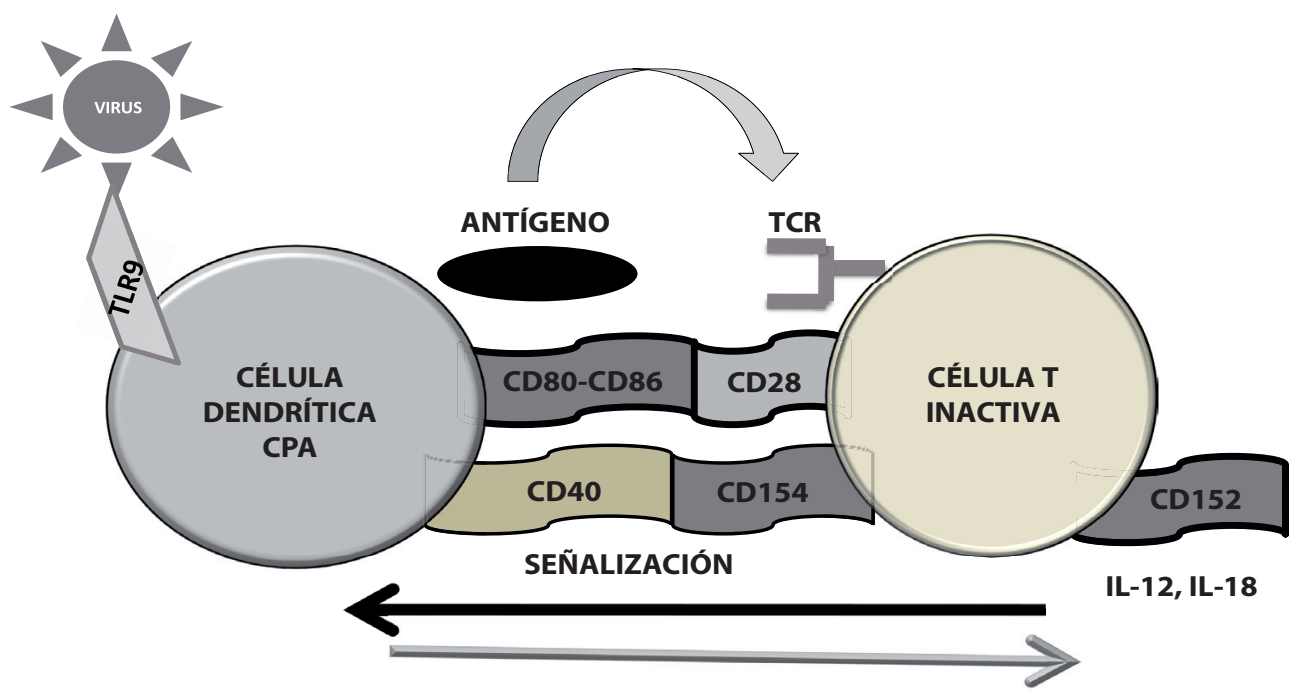

Figura 1. Proceso de activación de linfocitos T por medio de moléculas coestimuladoras entre 4 y 24 horas después de que el receptor de antígenos de linfocitos (TCR) ha sido activado por la presencia de antígenos. TLR9 (Receptor toll 9, receptor que reconoce el patrón molecular de virus); CPA (célula presentadora de antígeno); IL-12 (Interleuquina 12); IL-18 (interleuquina 18); CD80, CD86, CD28, CD40, CD154, CD152 (moléculas coestimulatorias que participan en la activación de los linfocitos T). 
y subsecuentemente, con la estimulación de IL-2, incrementa las proporciones de timocitos inmaduros CD4 (linfocito T de ayuda) y CD8 (linfocito T citotóxico) (35).

En macrófagos, la $P R L$ regula la síntesis de la sintetasa inducible de óxido nítrico, probablemente por la elevación de los niveles de calcio intracelular (36). Kumar et al (37), reportan que macrófagos tratados in vitro con PRL incrementan la producción de óxido nítrico e IL-1, probablemente vía activación PKC (Proteína quinasa C); asimismo, más recientemente, Tripathi y Sodhi (4) encontraron que, macrófagos tratados in vitro con $\mathrm{GH}$ y PRL mejoran la producción de óxido nítrico, sugiriendo un papel inmunomodulador de las dos hormonas.

Boutet et al (38), en un estudio en vacas con mastitis, reportaron que la PRL promueve una respuesta inflamatoria en las células epiteliales mamarias vía activación del factor nuclear NF- $\kappa$ B y aumenta significativamente la expresión de RNAm de citoquinas IL-6, IL-8, el factor estimulante de colonias de granulocitos y monocitos (GMCSF por sus siglas en inglés Granulocyte Macrophage Colony-Stimulating Factor) y TNF- $a$. Además, se ha demostrado que, la PRL participa en la regulación de la secreción de la inmunoglobulina A (IgA) en la leche, inhibiendo la colonización de bacterias patógenas (39).

Papel de HAMP en el sistema inmune. La HAMP es una hormona peptídica producida en los hepatocitos como respuesta al exceso de hierro (principal mecanismo redox intramitocondrial) y a estímulos inflamatorios. La HAMP disminuye la liberación de hierro por parte de la célula, por lo que es considerada un regulador negativo de la absorción de hierro en el intestino delgado y de su liberación por parte de los macrófagos. Ejerce su efecto bloqueante en el transporte de hierro en múltiples sitios y actúa como péptido antimicrobial (40). Esta hormona fue aislada en el año 2000 por Krause et al (41), a partir de plasma humano ultrafiltrado y fue descrita como LEAP-1 (liver-expresed antimicrobial peptide 1). Posteriormente, Park et al (42), aislaron este péptido a partir de la orina humana y comprobaron sus propiedades antimicrobianas. El nombre HAMP, proviene de los términos en inglés hepatic bactericidal proteines (hep) y de las propiedades antifúngicas y antibacterianas in vitro (cidin). Actualmente, se le conoce como HAMP (hepcidin antimicrobial peptide) (43).

La HAMP a la cual se le reconoce actividad es un péptido catiónico con 25 aminoácidos y 4 puentes disulfuro que unen los 8 residuos de cisteína (44), confiriéndole una carga total positiva y una tendencia a presentar estructuras secundarias anfipáticas, propiedad que permite a los péptidos antimicrobianos penetrar membranas de los microorganismos invasores (5).

Se han encontrado mecanismos homeostáticos para el hierro mediante la modulación de la expresión de la HAMP hepática, proporcionando al organismo resistencia a la infección (45). Experimentos realizados en ratones demuestran que los macrófagos, además, de los hepatocitos, expresan también HAMP en la estimulación de la activación de toll-like receptor 4 (TLR4) con LPS, generando efectos sistémicos o localizados en el sitio de la inflamación o de la invasión bacteriana (46).

La conexión entre HAMP y el metabolismo del hierro fue descrita por Nicolas et al (47), quienes trabajaron en el metabolismo de la glucosa relacionado con la transcripción del factor USF2, por sus siglas en inglés (upstream stimulatory factor 2) en ratones. La sobrecarga de hierro observada en estos ratones, se atribuye a la falta de HAMP y no a la deficiencia de USF2. En otro experimento, se concluyó que, la sobreproducción de HAMP da lugar a anemia severa en ratones, causada por la reducción de la absorción del hierro (48).

En el caso de enfermedades infecciosas, la mayoría de los patógenos altamente adaptados han desarrollado la capacidad de despojar al hospedero del hierro de proteínas tales como hemoglobina, transferrina y lactoferrina involucradas en el metabolismo del hierro (49).

En experimentos, la aplicación de endotoxinas en animales genera inflamación, estimulando la producción de HAMP que priva a los microorganismos invasores del hierro, mediante la inhibición de su absorción en el intestino y de su liberación por parte de los macrófagos (50). Un estudio in vitro en macrófagos de ratones reportó que la HAMP inhibe el crecimiento de Mycobacterium tuberculosis y, además, causa daño estructural a la micobacteria (51).

Por tanto, la HAMP no sólo es una hormona reguladora de hierro, es también un enlace importante entre el metabolismo del hierro, la defensa del hospedero y los procesos inflamatorios. La citoquina IL-6 es el inductor de la síntesis de esta hormona durante la inflamación (52). Esta interleuquina, induce la activación de la señalización de STAT3, que se une a la región promotora de la HAMP para activar su transcripción (6). Experimentos realizados en ratones han demostrado que, IL-6, IL- 1 a y la IL- $1 \beta$ estimulan la transcripción de HAMP; IL-10 tiene un efecto poco 
estimulante en la transcripción y el IFN- $\beta$ inhibe la transcripción de HAMP. IL-1 tiene la capacidad de aumentar la síntesis de óxido nítrico. Éste puede modular la homeostasis del hierro mediante el aumento de unión del hierro por medio de la proteína reguladora 1 (IRP1) a su elemento de respuesta (IRE) y mediante la aceleración de la degradación de la proteína reguladora 2 (IRP2), impidiendo su unión a sus objetivos de IRE. Por lo tanto, parecía posible que el óxido nítrico pudiera servir como mediador en la transcripción de HAMP en situaciones de sobrecarga de hierro, en especial en las vías inflamatorias. Se ha sugerido que, IL-1 no posee efecto estimulante sobre la transcripción de HAMP, pero se ha demostrado en ratones que con IL- 6 deficiente se mantiene la capacidad de responder a desafíos de endotoxina. Otros estudios concluyen que, es posible que la estimulación de la HAMP por la IL-1 juegue un papel importante en la anemia inflamatoria (51).

En conclusión, de acuerdo con las investigaciones que se han realizado hasta este momento, es evidente el papel que desempeña GH, PRL y HAMP en la interacción y comunicación bidireccional entre el SI y endocrino. Las 3 hormonas pueden actuar a través de diferentes rutas de señalización, desempeñando papeles ya sea como inmunomoduladores, reguladores metabólicos o péptidos antimicrobianos.

Como nuevas perspectivas, existen grandes avances en investigación sobre la interacción entre el SI y el sistema neuroendocrino. Cada vez hay mayor claridad en los efectos y los mecanismos por los cuales interactúan los dos sistemas; sin embargo, los procesos de regulación y mecanismos intracelulares aún están parcialmente conocidos. Se ha demostrado que, tanto el sistema neuroendocrino como el SI, interactúan a través de hormonas, neurotransmisores y citoquinas y dentro de estas investigaciones se reporta que $\mathrm{GH}$ y PRL mejoran la timopoyesis y el desarrollo de las células T. Por lo tanto, se podría visualizar a estas hormonas como posibles terapéuticos para ser utilizados en casos de inmunodeficiencia.

Conjuntamente, la HAMP también podría representar otra posibilidad terapéutica en casos infecciosos, ya que, ha sido descrita como un péptido antimicrobiano por su tendencia a presentar estructuras anfipáticas secundarias, capacidad que le permite penetrar membranas de microorganismos invasores, además de, privarlos de la captación de hierro.

Por otra parte, después del descubrimiento de la HAMP, gran cantidad de investigaciones apuntan a que esta hormona y sus reguladores, pueden ser utilizados para el diagnóstico y clasificación de desórdenes del metabolismo del hierro, aparte de poseer un considerable potencial terapéutico para el tratamiento, ya sea de excesos de hierro, anemia o de inflamación. Sin embargo, la regulación y mecanismos intracelulares de su secreción y su importancia biológica, necesitan de mayor investigación.

\section{REFERENCIAS}

1. Kelley KW, Weigent DA, Kooijman R. Protein Hormones and Immunity. Brain Behav Immun 2007; 21(4):384-392.

2. O'Connor JC, McCusker RH, Strle K, Johnson RW, Dantzer R, Kelley KW. Regulation of IGF-I function by proinflammatory cytokines: at the interface of immunology and endocrinology. Cell Immunol 2008; 252:91-110.

3. Redelman D, Welniak LA, Taub D, Murphy WJ. Review Neuroendocrine hormones such as growth hormone and prolactin are integral members of the immunological cytokine network. Cel Immunol 2008; 252:111-121.

4. Tripathi A, Sodhi A. Production of nitric oxide by murine peritoneal macrophages in vitro on treatment with prolactin and growth hormone: Involvement of protein tyrosine kinases, $\mathrm{Ca}++$, and MAP kinase signal transduction pathways. Mol Immunol 2007; 44:3185-3194.
5. Falzacappa MV, Muckenthaler MU. Hepcidin: iron-hormone and anti-microbial peptide. Gene 2005; 364:37-44.

6. Verga Falzacappa MV, Vujic Spasic M, Kessler R, Stolte J, Hentze MW, Muckenthaler MU. STAT3 mediates hepatic hepcidin expression and its inflammatory stimulation. Blood 2007; 109:353-358.

7. Carroll JA. Bidirectional communication: Growth and immunity in domestic livestock. J Anim Sci 2008; 86:E126-E137.

8. Hattori N. Review Expression, regulation and biological actions of growth hormone $(\mathrm{GH})$ and ghrelin in the immune system. Growth Horm IGF Res 2009; 19:187-197.

9. Elenkov LJ. Neurohormonal-cytokine interaction; implication for inflammation, common human diseases and well-being. Neurochem Int 2008; 52:40-51. 
10. Torres RC, Aguilar F. Relación anatómica, clínica y neurofisiológica entre los sistemas nervioso, endocrino e inmune. Plast \& Rest Neurol 2006; 5(1): 75-84.

11. Mocchegiani E, Santarelli L, Costarelli L, Cipriano C, Muti E, Giacconi R, Malavolta $M$. Plasticity of neuroendocrine-thymus interactions during ontogeny and ageing: role of zinc and arginine. Ageing Res Rev 2006; 5:281-309.

12. Peyssonnaux C, Zinkernagel AS, Datta V, et al. TLR4-dependent hepcidin expression by myeloid cells in response to bacterial pathogens. Blood 2006; 107:3727-3732.

13. Pinto JP, Dias V, Zoller H, Porto G, Carmo H, Carvalho $\mathrm{F}$ et al.Hepcidin messenger RNA expression in human lymphocytes. Immunol 2010; 130:217-230.

14. Borghetti $P$, Saleri $R$, MocchegianiE, Corradi A, Martelli P. Infection, immunity and the neuroendocrine response. Vet Immunol Immunopathol 2009; 130:141-162.

15. Correa Silvia G, Maccioni M, Rivero VE, Iribarren $\mathrm{P}$, Sotomayor CE, Riera CM. Cytokines and the immune-neuroendocrine network: what did we learn from infection and autoimmunity? Cytokine Growth Factor Rev 2007; 18:125-134.

16. Vijayakumar A, Novosyadlyy R, Wu Y, Yakar S, LeRoith D. Biological effects of growth hormone on carbohydrate and lipid metabolism. Growth Horm IGF Res 2010; 20:1-7.

17. Kojima M, Hosada $H$, Date $Y$, Nakazato $M$, Matsuo $H$, Kangawa K. Ghrelin is a growthhormone-releasing acylated peptide from stomach. Nat 1999; 402:656-60.

18. ThanThan S, Mekaru C, Seki N, Hidaka K, Ueno A, ThidarMyint $\mathrm{H}$ et al. Endogenous ghrelin released in response to endothelin stimulates growth hormone secretion in cattle. Domest Anim Endocrinol 2010; 38(1):1-12.

19. Sodhi A, Tripathi A. Prolactin and growth hormone induce differential cytokine and chemokine profile in murine peritoneal macrophages in vitro: Involvement of p_38 MAP kinase, STAT3 and NF_ $\kappa$ B. Cytokine 2008; 41:162-173.
20. Baeza I, Alvarado C, Ariznavarreta C, Castillo C, Tresguerres JA, De la Fuente $M$. Effect of growth hormone treatment on lymphocyte functions in old male rats. Neuroimmunomodulation 2008; 15(4-6): 279-284.

21. Baeza I, Alvarado C, Álvarez P, Salazar V, Castillo C, Ariznavarreta C, et al. Improvement of leucocyte functions in ovariectomised aged rats after treatment with growth hormone, melatonin, oestrogens or phyto-oestrogens. J Reprod Immunol. 2009; 80(1):70-79.

22. Frare EO, Elena Santello F, Caetano LC, Caldeira JC, Toldo MP, Prado JC. Growth hormones therapy in immune response against Trypanosoma cruzi. Res Vet Sci 2010; 88:273-278.

23. Briard, N., V. Guillaume, C. Frachebois, M. Rico-Gomez, N. Sauze, C. Oliver, and A. Dutour. Endotoxin injection increases growth hormone and somatostatin secretion in sheep. Endocrinol 1998; 139:2662-2669.

24. Briard N, Dadoun F, Pommier G, Sauze N, Lebouc $Y$, Oliver $C$ et al. IGF-1/IGFBPs system response to endotoxin challenge in sheep. J Endocrinol 2000; 164:361-369.

25. Priego T, Granado M, Ibañez de Cáceres I, Martín AI, Villanúa MA, Calderón A. Endotoxin at low doses stimulates pituitary $\mathrm{GH}$ whereas it decreases IGF-I and IGFBP-3 in rats. J Endocrinol 2003; 179:107-17.

26. Daniel JA, Elsasser TH, Martinez A, Steele B, K. Whitlock BK,Sartin JL. Interleukin-1beta and tumor necrosisfactor-alpha mediation of endotoxin action on growth hormone. Am J Physiol Endocrinol Metab 2005. 289: E650-E657.

27. Priego T, Granado M, Ibañez de Cáceres I, Martín AI, Villanúa MA, Calderón A. Endotoxin administration increases hypothalamic somatostatin mRNA through nitric oxide release. Regulat Pept 2005; 124:113-118.

28. Wang X, Jiang J, Warram J, Baumann G, Gan Y, MenonR et al. Endotoxin-Induced Proteolytic Reduction in Hepatic Growth Hormone (GH) Receptor: A Novel Mechanism for GH Insensitivity. Mol Endocrinol 2008; 22 : 1427-1437.

29. Rogatsky I, Ivashkiv LB. Review Article Glucocorticoid modulation of cytokine signaling. J compilation 2006; 68:1-12. 
30. Tripathi A, Sodhi A. Growth hormone-induced production of cytokines in murine peritoneal macrophages in vitro: Role of JAK/STAT, PI3K, PKC and MAP kinases. Immunobiol 2009; 214:430-440.

31. Sodhi A, Tripathi A. Prolactin and growth hormone induce differential cytokine and chemokine profile in murine peritoneal macrophages in vitro: Involvement of $p-38$ MAP kinase, STAT3 and NF_ $\kappa$ B. Cytokine 2008; 41:162-173.

32. Tripathi A, Sodhi A. Prolactin-induced production of cytokines in macrophages in vitro involves JAK/STAT and JNK MAPK pathways. International Immunol 2007; 20 (3):327-336.

33. Xu D, Lin L, Lin X, Huang $Z$, Lei $Z$. Immunoregulation of autocrine prolactin: Suppressing the expression of costimulatory molecules and cytokines in T lymphocytes by prolactin receptor knockdown. Cel Immunol 2010; 263(1):77-78.

34. Nemirovsky MS, Homberg JC. Fundamentos de inmunología. Bases estructurales, fisiológicas y fisiopatologías de la respuesta inmune. México: Trillas; 2003.

35. Carreño PC, Sacedón R, Jiménez E, Vicente, Zapata AG. Prolactin affects both survival and differentiation of T-cell progenitors.J Neuroimmunol 2005; 160:135-145.

36. Bolander J. Prolactin activation of mammary nitric oxide synthase: molecular mechanisms. J Mol Endocrinol 2002; 28:45-51.

37. Kumar A, Singh SM, Sodhi A. Effect of prolactin on nitric oxide and interleukin-1 production of murine peritoneal macrophages: Role of $\mathrm{Ca}^{2+}$ and protein kinace C. Int Societ immunopharmacol 1997; 19 (3): 129-133.

38. Boutet $P$, Sulon J, Closset R, DetilleuxJ, Beckers J, Bureau F et al. Prolactin-Induced Activation of Nuclear Factor $\kappa \mathrm{B}$ in Bovine Mammary Epithelial Cells: Role in Chronic Mastitis. J Dairy Sci 2007; 90:155-164.

39. Vorbach C, Capecchi MR, Penninger JM. Evolution of the mammary gland from the innate immune system?. BioEssays 2006; 28:606-616.

40. Hugman A. Hepcidin: an important new regulator of iron homeostasis. Clin Lab Haematol 2006; 28(2):75-83.
41. Krause A, Neitz S, Mägert HJ, Schulz A, Forssmann WG, Schulz Knappe P, Adermann K. LEAP-1, a novel highly disulfide-bonded human peptide, exhibits antimicrobial activity. FEBS Lett. Antimicrobial activity. FEBS Lett 2000; 480:147-150.

42. Park $\mathrm{CH}$, Valore $\mathrm{EV}$, Waring $\mathrm{AJ}$, Ganz $\mathrm{T}$. Hepcidin, a urinary antimicrobial peptide synthesized in the liver. J BiolChem SA 2001; 276:7806-7810.

43. Nemeth E, Ganz T. Regulation of iron metabolism by hepcidin. Annu Rev Nutr 2006; 26:323-342.

44. Del Castillo A, De Portugal J. Hepcidina, una nueva proteína en la homeostasis del hierro. An Med Interna 2003; 20:605-606.

45. Andrews N, Schmidt P. Iron Homeostasis. Annu Rev Physiol 2007; 69:69-85.

46. Zhang S, Enns C. Iron Homeostasis: Recently Identified Proteins Provide Insight into Novel Control Mechanisms. J Biol.Chem 2009; 284(2):711-715.

47. Nicolas G, Bennoun M, Devaux I, et al. Lack of hepcidin gene expression and severe tissue iron overload in upstream stimulatory factor 2 (USF2) knockout mice. PNAS 2001; 98:8780-8785.

48. Nicolas $G$, Bennoun M, Porteu A, Mativet S, Beaumont C, Grandchamp B. Severe iron deficiency anemia in transgenic mice expressing liver hepcidin. PNAS 2002; 99: 4596-4601.

49. Ganz T. Hepcidin, a key regulator of iron metabolism and mediator of anemia on inflammation. Blood 2003; 103(3):783-788.

50. Lee P, Peng H, Gelbart T, Wang L, Beutler E. Regulation of hepcidin transcription by interleukin-1 and interleukin-6. PNAS 2005; 102(6): 1906-1910.

51. Sow FB, Florence WC, Satoskar AR, Schlesinger LS, Zwilling BS, Lafuse WP. Expression and localization of hepcidin in macrophages: a role in host defense against tuberculosis. J Leukoc Biol 2007; 82:934-945.

52. Nemeth E. Regulation of iron metabolism by hepcidin. Annu Rev Nutr 2006; 26:323-42. 